Article

\title{
A Piscine Birnavirus Induces Inhibition of Protein Synthesis in CHSE-214 Cells Primarily through the Induction of eIF2 $\alpha$ Phosphorylation
}

\author{
Amr A.A. Gamil, Stephen Mutoloki and Øystein Evensen * \\ Faculty of Veterinary Medicine and Biosciences, Norwegian University of Life Sciences, \\ P.O. Box 8146 Dep., 0033 Oslo, Norway; E-Mails: amr.gamil@nmbu.no (A.A.A.G.); \\ stephen.mutoloki@nmbu.no (S.M.) \\ * Author to whom correspondence should be addressed; E-Mail: oystein.evensen@nmbu.no; \\ Tel.: +47-22-59-76-01; Fax: +47-22-96-73-10. \\ Academic Editor: Eric O. Freed
}

Received: 27 February 2015 / Accepted: 10 April 2015 / Published: 15 April 2015

\begin{abstract}
Inhibition of protein synthesis represents one of the antiviral mechanisms employed by cells and it is also used by viruses for their own propagation. To what extent members of the Birnaviridae family employ such strategies is not well understood. Here we use a type-strain of the Aquabirnavirus, infectious pancreatic necrosis virus (IPNV), to investigate this phenomenon in vitro. CHSE-214 cells were infected with IPNV and at 3, 12,24 , and 48 hours post infection (hpi) before the cells were harvested and labeled with $\mathrm{S}^{35}$ methionine to assess protein synthesis. eIF $2 \alpha$ phosphorylation was examined by Western blot while RT-qPCR was used to assess virus replication and the expression levels of IFN- $\alpha$, Mx1 and PKR. Cellular responses to IPNV infection were assessed by DNA laddering, Caspase- 3 assays and flow cytometry. The results show that the onset and kinetics of eIF $2 \alpha$ phosphorylation was similar to that of protein synthesis inhibition as shown by metabolic labeling. Increased virus replication and virus protein formation was observed by $12 \mathrm{hpi}$, peaking at $24 \mathrm{hpi}$. Apoptosis was induced in a small fraction (1-2\%) of IPNV-infected CHSE cells from 24 hpi while necrotic/late apoptotic cells increased from $10 \%$ by $24 \mathrm{hpi}$ to $59 \%$ at $48 \mathrm{hpi}$, as shown by flow cytometry. These results were in accordance with a small decline in cell viability by $24 \mathrm{hpi}$, dropping below $50 \%$ by $48 \mathrm{hpi}$. IPNV induced IFN- $\alpha$ mRNA upregulation by 24 hpi while no change was observed in the expression of Mx1 and PKR mRNA. Collectively, these findings show that IPNV induces inhibition of protein synthesis in CHSE cells through phosphorylation of eIF2 $\alpha$ with minimal
\end{abstract}


involvement of apoptosis. The anticipation is that protein inhibition is used by the virus to evade the host innate antiviral responses.

Keywords: Birnavirus; infectious pancreatic necrosis virus; eIF2 $\alpha$; inhibition of protein synthesis; Mx; apoptosis

\section{Introduction}

Cells employ inhibition of protein synthesis as a defensive mechanism in response to virus invasion, the aim being to limit the production of virus progeny and consequently arrest the spread within the organism. In higher vertebrates, there are mainly three well-known mechanisms by which inhibition of protein synthesis is induced during virus infections: (1) through the activation of the interferon inducible, dsRNA-activated protein kinase R (PKR); (2) through the activation of the PKR-like endoplasmic reticulum (ER) kinase (PERK); and 3) through factors associated with the induction of apoptosis. PKR is activated and auto-phosphorylated upon recognition and binding of dsRNA to its binding motif in the $\mathrm{N}$ terminus [1]. Phosphorylated PKR in turn phosphorylates the eukaryotic initiation factor 2-alpha (eIF2 $\alpha$ ). eIF2 $\alpha$ phosphorylation blocks eIF2B-mediated GDP-GTP exchange preventing the formation of GTP-eIF2-tRNAi ${ }^{\text {Met }}$ ternary complex, which is crucial for translation initiation, and results in translation inhibition [2]. eIF2 $\alpha$ phosphorylation can also be induced through PERK which is activated due to the accumulation of unfolded protein in the ER lumen, as a result of high virus replication, leading to the initiation of what is known as the unfolded protein response (UPR) [3]. Apoptosis on the other hand is induced by many innate and adaptive antiviral mechanisms [4], thereby leading to the activation of intracellular caspases during the early stages of apoptosis. Some of the caspases executing apoptosis can target components of the translation machinery for proteolysis [5].

Viruses, as obligatory pathogens, depend on the host machinery to produce their own proteins. They have evolved different strategies of taking advantage of the host machinery of protein synthesis that may or may not be associated with inhibition of protein synthesis. Picorna- and rotaviruses break translational control by targeting and disrupting different components of the translational apparatus [6-8]. As a result, the cells lose control of the translation machinery leading to the inhibition of host protein synthesis $[9,10]$. Other viruses such as adeno- and herpesviruses disrupt the regulatory pathway that inhibits protein synthesis in response to virus infection through PKR activation [11,12]. For birnavirus infections, there are no studies that clearly demonstrate how inhibition of protein synthesis occurs and to whose benefit.

IPNV is a type species of the genus Aquabirnavirus. It is an icosahedral, non-enveloped, doublestranded RNA virus consisting of two segments [13]. The first segment (A) is 3,092 bp long and contains two overlapping open reading frames (ORFs): a short one encoding a non-structural protein VP5 [14,15] and a long ORF encoding structural proteins VP2 and VP3 as well as a non-structural protein VP4 [16,17]. Segment B is 2,784 bp long and contains only one ORF encoding the viral polymerase VP1 [18]. Early studies using a piscine birnavirus infectious pancreatic necrosis virus (IPNV) showed that the virus was not associated with inhibition of protein synthesis although it suppressed DNA synthesis in permissive host cells $[19,20]$. In another study characterizing eIF $2 \alpha$ and its response to endoplasmic reticulum stress, IPNV phosphorylated eIF2 $\alpha$ [21], suggesting that inhibition of protein synthesis is in fact induced 
although this was not the focus of the study. In a recent study, Chen et al. showed that a low virulent recombinant strain of IPNV is able to induce inhibition of protein synthesis in RTG-2 cells [22]. In the present study, we demonstrate not only that this virus induces inhibition of protein synthesis in CHSE-214 cells but also that the virus probably uses this mechanism to its advantage.

\section{Materials and Methods}

\subsection{Cell Lines}

Chinook salmon embryonic (CHSE-214) [23] and Asian Grouper strain K (AGK) [24] cells were maintained in L-15 media with Glutamax ${ }^{\circledR}$ (Gibco, Carlsbad, CA, USA) supplemented with 5\% FBS (Sigma Aldrich, St. Louis, MO, USA). For maintenance, CHSE-214 cells were grown at $20^{\circ} \mathrm{C}$ while AGK cells were kept at $28^{\circ} \mathrm{C}$.

\subsection{Virus Propagation}

A recombinant IPN virus $\left(\mathrm{rNVI}-15 \mathrm{R}^{\mathrm{b}}\right.$ ) previously produced by reverse genetics [25] was used. In order to obtain adequate amounts of virus for use in the inhibition of protein synthesis experiment, the virus was first inoculated into $70 \%-80 \%$ confluent AGK cells followed by incubation at $15{ }^{\circ} \mathrm{C}$ until full CPE. The supernatant containing the virus was then harvested and clarified by centrifugation at $2500 \mathrm{rpm}$ for $10 \mathrm{~min}$. The concentration of the virus was estimated by titration in 96-well plates (Falcon, Bedford, MA, USA) containing 80\%-90\% confluent CHSE cells.

\subsection{Virus Infection and Metabolic Labeling}

Six-well plates containing approximately 90\% confluent CHSE cells were used. Inoculation of cells in wells was done sequentially, one well for each time point to yield cells infected either for 3, 12, 24 or $48 \mathrm{~h}$ by the time of sampling. The cells were infected at a multiplicity of infection (MOI) of 20 with the purpose of obtaining one-cycle infection kinetics, and the experiment was repeated four times.

Level of protein synthesis was evaluated by monitoring $\mathrm{S}^{35}$ methionine incorporation into proteins. Cells were washed $3 \times$ with PBS followed by incubation with Methionine, Lysine and L-glutamine free Dulbecco's modified Eagle's medium (sigma Aldrich) containing $20 \mu \mathrm{Ci} / \mathrm{mL} \mathrm{S}^{35}$ Methionine (Hartmann analytic, Braunschweig, Germany), 1\% L-glutamine (Sigma Aldrich) and 2\% FBS for 30 min. Thereafter, the cells were washed once with PBS, lysed using $250 \mu \mathrm{L}$ Cell M lysing reagent (Sigma Aldrich) and then slowly agitated for $15 \mathrm{~min}$. Cells were then scraped from the wells and transferred to $1.5 \mathrm{~mL}$ Eppendorf tubes together with the supernatants. Lysates were centrifuged at 13,000 rpm for $5 \mathrm{~min}$ to remove the cell debris and nucleus. Finally, the supernatants were transferred to new Eppendorf tubes and kept at $-80{ }^{\circ} \mathrm{C}$ until required.

To evaluate the level of protein synthesis, cell lysates were subjected to gel electrophoresis. $10 \mu \mathrm{g}$ of total cell proteins from each sample was applied to a Nupage mini gel (Invitrogen, Carlsbad, CA, USA) and subjected to electrophoresis at $200 \mathrm{~V}$. The separated proteins were transferred from the gel to a PVF membrane using a semi-dry blotter (Biorad, Hercules, CA, USA). The membrane was incubated in a storage phosphor cassette overnight. Finally, radioactivity was detected using the Typhoon (GE Healthcare, Piscataway, NJ, USA). 


\subsection{Western Blot Analysis}

Following radioactivity detection, the membranes were rehydrated in Tris buffer saline with $0.5 \%$ Tween $20(0.5 \%$ TBST). Of the non-fat dry milk (Biorad), 5\% was prepared in $0.1 \%$ TBST and was used to block non-specific reactions. The membrane was then probed by using antibodies against actin (Sigma Aldrich), eIF2 $\alpha$ and phosphorylated eIF2 $\alpha$, ser51 (peIF2 $\alpha$ ) (Cell Signaling, Beverly, MA, USA) while aliquots from the same sample were used in another blot to detect virus protein synthesis using K95 polyclonal rabbit anti-IPNV [26]. This was followed by incubation with HRP-labeled secondary antibodies. The signal was developed using SuperSignal West Dura Extended Duration Substrate (Pierce) and detected using the Typhoon (GE healthcare). After the first detection, the membrane was washed twice with $0.1 \%$ TBST, stripped using Restore ${ }^{\mathrm{TM}}$ Plus buffer (Pierce, Rockford, IL, USA), washed twice as above, and re-probed with a new primary antibody and developed as already described.

\subsection{Cell Viability Assay}

Cell viability at different times post IPNV infection was determined by using CellTiter 96® AQueous One Solution Assay (Promega, Madison, WI, USA). The assay measures the reduction of a tetrazolium compound by the cells into a colored formazan product, which is directly correlated to the cell number. Confluent CHSE-214 cells seeded in 96-well plates (Corning, Life Science, Lowell, CA, USA) were infected with IPNV as described above or left uninfected. Cells were kept at $15^{\circ} \mathrm{C}$ during the infection period. At 3, 12, 24 and $48 \mathrm{hpi}, 20 \mu \mathrm{L}$ of the CellTiter $96{ }^{\circledR}$ AQueous One Solution reagent was added to the cells. Cells were incubated at $20^{\circ} \mathrm{C}$ for $6 \mathrm{~h}$ and the absorbance at $490 \mathrm{~nm}$ was measured using a GENios microplate reader (Tecan, Männedorf, Switzerland). The viability was calculated and expressed as a percentage of the $\mathrm{OD}_{490}$ values obtained from the corresponding controls.

\subsection{Assessment of Apoptosis by DNA Fragmentation}

The fragmentation of DNA was assessed by using Apoptotic DNA Ladder Kit (Roche, Basel, Switzerland). Six-well plates containing confluent CHSE cells were used for this purpose. Cells were infected in quadruplicates with IPNV as described above while the remaining two wells were left uninfected as negative controls. Infected cells were sampled at 3, 12, 24 and $48 \mathrm{~h}$ post infection, while untreated cells were sampled at $48 \mathrm{~h}$ post infection. Cells were harvested by lysis using $400 \mu \mathrm{L}$ binding/lysis buffer diluted v/v in PBS. Following incubation for $10 \mathrm{~min}, 100 \mu \mathrm{L}$ isopropanol was added and mixed with the sample. The samples were then loaded in polypropylene tubes containing two layers of glass fiber fleece, washed using washing buffer, and finally eluted in $200 \mu \mathrm{L}$ elution buffer. Samples were treated with $2 \mu \mathrm{g} / \mathrm{mL}$ DNase free RNase (Roche) before being analyzed by gel electrophoresis.

\subsection{Caspase 3 Assay}

The activity of caspase 3 in the cell lysates was assessed by using the Caspase-Glo ${ }^{\circledR} 3 / 7$ assay kit (Promega) following the protocol as described by the manufacturer. Briefly, CHSE-214 cells were seeded in white-walled 96-well plates (Corning) to a final density of $10^{4}$ cells/well and incubated for about $14 \mathrm{~h}$. Cells were then infected with IPNV in triplicates sequentially as already described above. Duplicates of uninfected cells or cells treated with $2.5 \mu \mathrm{M}$ staurosporine for 3, 12, 24 and $48 \mathrm{~h}$ were 
included as negative and positive controls, respectively. At the time of sampling, the volume of media in the wells was adjusted to $50 \mu \mathrm{L}$ and equal volumes of Caspase-Glo ${ }^{\circledR} 3 / 7$ were added to each well. Cells were incubated at room temperature for 1 hour prior to bioluminescence reading $(490 \mathrm{~nm}) \mathrm{using}$ a GENios microplate reader (Tecan). The results were calculated by subtracting the mean values obtained from the control samples from the readings obtained from each well. The whole experiment was repeated twice.

\subsection{Assessment of Apoptosis by Flow Cytometry}

Six-well plates containing confluent CHSE cells were used in a similar setup as the one described in the section above. In addition, three parallel wells in a separate plate were treated with $2.5 \mu \mathrm{M}$ staurosporine for 12,24 or $48 \mathrm{~h}$ as positive controls of apoptosis. During each sampling, the supernatant was transferred to a $5 \mathrm{~mL}$ polystyrene round-bottomed tube (BD Biosciences, San Jose, CA, USA) while adherent cells were washed twice with PBS prior to trypsinization. Trypsinization was done for $5 \mathrm{~min}$ following which the reaction was stopped by adding fresh media. The trypsinized cells were then pooled with the original supernatant in the $5 \mathrm{~mL}$ polystyrene tubes. The cells were pelleted by centrifugation at $300 \times g$ for $10 \mathrm{~min}$. The supernatant was then removed and cells were re-suspended in $100 \mu \mathrm{L}$ Hepes buffer containing $2 \mu \mathrm{L}$ fluorescein conjugated annexin-V staining reagent (Annexin-V-FLUOS Staining Kit, Roche). After incubating for $30 \mathrm{~min}$, the volume was adjusted to $300 \mu \mathrm{L}$. To differentiate between apoptotic and necrotic cells, membrane permeability was assessed by adding propidium iodide (PI) (Sigma Aldrich), just before the analysis to a final concentration of $8 \mu \mathrm{g} / \mathrm{mL}$. Flow cytometry was performed for 30,000 events using a BD FACSARIA ${ }^{\mathrm{TM}}$ cell sorter (BD) while data analysis was performed using BD FACS DiVa Software, version 5.0.2 (BD).

The following parameters were measured to identify the apoptotic cells: (1) the area pulse of forward light scatter (FSC-A) versus side scatter (SSC-A), and (2) fluorescent intensities of FITC (filter 530/30) and PI (filter 630/30) upon excitation with $20 \mathrm{~mW} 488 \mathrm{~nm}$ laser. Cell aggregates were identified and excluded by using the width pulse of FSC-A versus area width of SSC-A. The whole experiment was repeated four times.

\subsection{Quantitative Real-Time PCR Analysis}

To assess the level of replication of IPNV as well as the expression of IFN $\alpha, M x 1$ and PKR, real-time RT-qPCR was used. Cells were infected with IPNV as described above with the exception that this time three parallels were used per treatment. In addition, one parallel of cells was treated with IFN $\alpha$ for 4 days, as described previously, [27] as a control.

Total RNA was isolated by using the RNeasy Plus minikit (Qiagen, Hilden, Germany) according the manufacturer's instructions and the concentration of RNA was determined by using the Nanodrop ND1000 (NanoDrop technologies, Wilmington, DE, USA). Of total RNA, 400 ng from each sample were used to synthesize cDNA using a Transcriptor first-strand cDNA synthesis kit (Roche) according to the manufacturer's instructions. The cDNA was diluted five times and stored at $-20{ }^{\circ} \mathrm{C}$ until required.

Quantitative PCR was performed in 96-well plates using the LightCycler 480 system (Roche). For each reaction, $2 \mu \mathrm{L}$ cDNA was mixed with 10 pmol gene-specific primers and $10 \mu \mathrm{L}$ LightCycler 480 
SYBR green I master mix (Roche). The final concentration was adjusted to $20 \mu \mathrm{L}$ using RNase-free water. The sequences of primers used in the reactions are provided in Table 1.

The cycling conditions for the PCR reactions were as follows: denaturation $94{ }^{\circ} \mathrm{C}$ for $10 \mathrm{~s}$; annealing $60{ }^{\circ} \mathrm{C}$ for $10 \mathrm{~s}$; elongation $72{ }^{\circ} \mathrm{C}$ for $10 \mathrm{~s}$. The results were analyzed by the $\Delta \Delta \mathrm{CT}$ relative quantification approach [28] using $\beta$-actin as reference gene. Graphs were drawn with the help of GraphPad Prism 5.0 (GraphPad Software Inc., San Diego, CA, USA).

Table 1. Primer sequences used for real-time PCR

\begin{tabular}{lll}
\hline Name & Primer sequence (5'-3') & Genbank accession no. \\
\hline Mx-Forward & TGCAACCACAGAGGCTTTGAA & U66475 \\
Mx-Reverse & GGCTTGGTCAGGATGCCTAAT & AF012125 \\
\hline B actin Forward & CCAGTCCTGCTCACTGAGGC & \\
B actin Reverse & GGTCTCAAACATGATCTGGGTCA & \multirow{2}{*}{ EF523422.1 } \\
\hline PKR Forward & TGAACACAGCCAGAAGAACAA & \\
PKR Reverse & GACTACCGCCACATAACTCCA & \\
\hline IPNv Forward & CAACAGGGTTCGACAAACCATAC & NM_001123570.1 \\
IPNv Reverse & TTGACGATGTCGGCGTTTC & \\
\hline IFN $\alpha$ Forward & TGGGAGGAGATATCACAAAGC & \\
IFN $\alpha$ Reverse & TCCCAGGTGACAGATTTCAT &
\end{tabular}

\subsection{Statistical Analysis}

For the caspase assay, two-way analysis of variance was used to test for differences between staurosporine-treated and infected cells followed by the Bonferroni test to compare the mean of each treatment to the mean of the RLU values obtained at $3 \mathrm{~h}$. An Anova test was performed to assess reduction in protein synthesis and viability with a Dunnett post hoc test using GraphPad Prism 5.0 (GraphPad Software Inc.).

\section{Results}

\subsection{Virus Replication in CHSE-214 Cells}

Initially, we wanted to establish a system by which virus replication and its effect on cellular responses could be monitored over a short period of time thereby allowing, us to assess the effect of virus infection from the early replication stages until the endpoint in cell culture. We found that infection with $20 \mathrm{pfu} / \mathrm{cell}$ results in appearance of evident CPE by $48 \mathrm{~h}$ from the time of infection (Figure 1). 

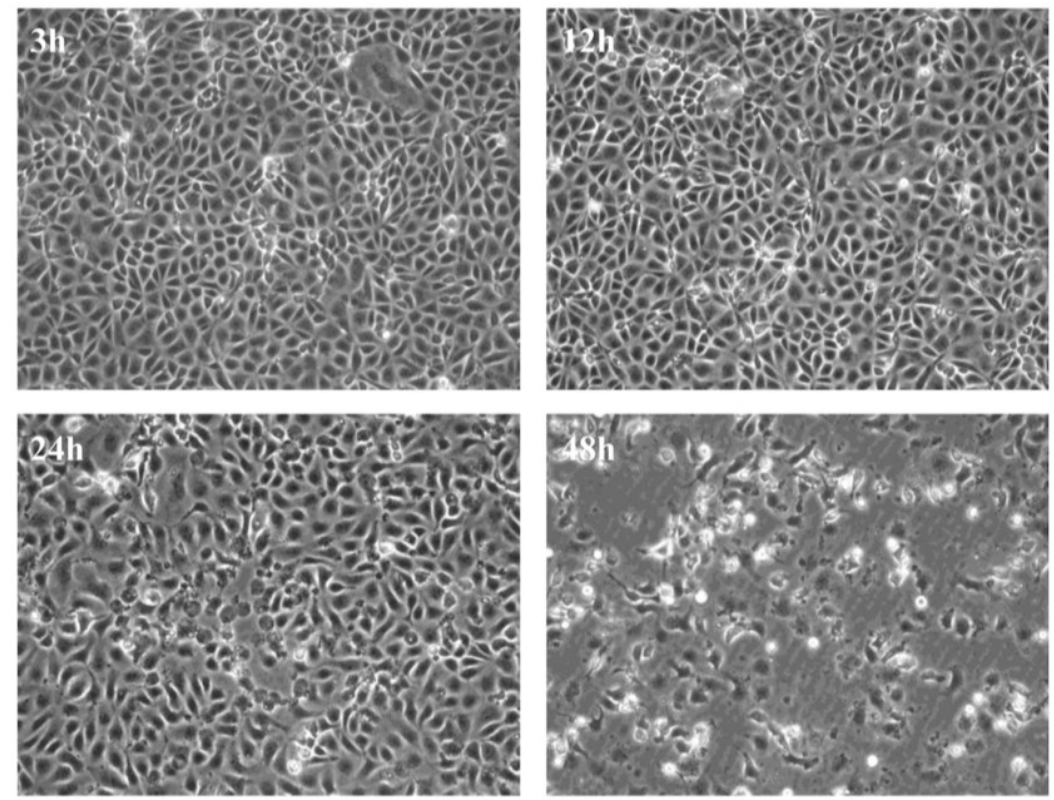

Figure 1. Cytopathic effects in CHSE cells. Development of cytopathic effect in CHSE-214 cells infected with recombinant strain rNVI-15R $\mathrm{R}^{\mathrm{b}}$ of infectious pancreatic necrosis virus.

\subsection{Virus Replication Results in Inhibition of Protein Synthesis}

After establishing our infection model we examined protein synthesis in CHSE cells infected with IPNV at different times post infection (p.i.). At three hours p.i. (hpi), no difference in protein synthesis was observed between infected cells and uninfected controls (Figure 2a). At 12 and 24 hpi, however, a progressive reduction in protein synthesis was observed in infected cells, initially with a moderate reduction at $12 \mathrm{~h}(80 \%$ protein synthesis compared to uninfected controls; $p<0.01)$ followed by a marked reduction at $24 \mathrm{hpi}, 65 \%$ reduction compared to uninfected controls (Figure $2 \mathrm{~b}, p<0.001$ ). The loss of cell viability was $6 \%(p<0.05)$ and $9 \%(p<0.01)$, respectively, at these time points (Figure $2 c)$, showing a pronounced reduction in protein synthesis with marginal reduction in viability.

\subsection{Virus Replication Increases despite Inhibition of Host Protein Synthesis at Early Time}

\section{Post Infection}

Next we wanted to investigate whether inhibition of protein synthesis has any effect on virus replication. We first examined IPNV replication at different stages of infection by real-time RT-qPCR using primers specific for the virus VP2 protein. The results show that the viral mRNA levels increased rapidly in CHSE cells, peaking at $24 \mathrm{~h}$ (Figure 3a). Since production of new viruses can be inhibited at the translation level, we used Western blot as an additional tool to monitor the production of virus proteins. Our results showed that inhibition of protein synthesis had no effect on production of virus proteins (Figure 3b). 


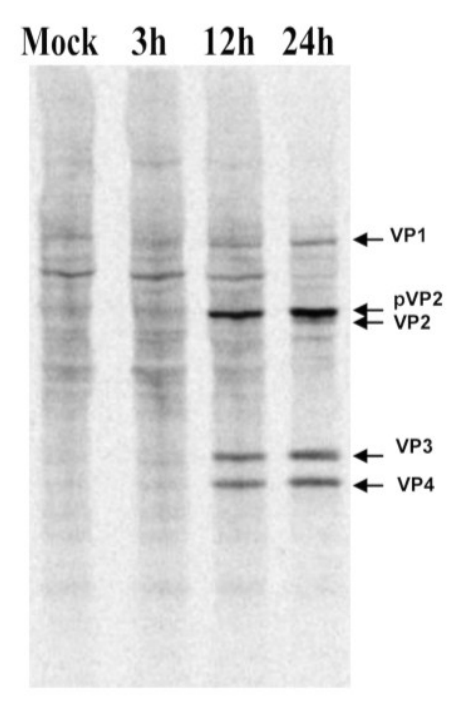

(a)

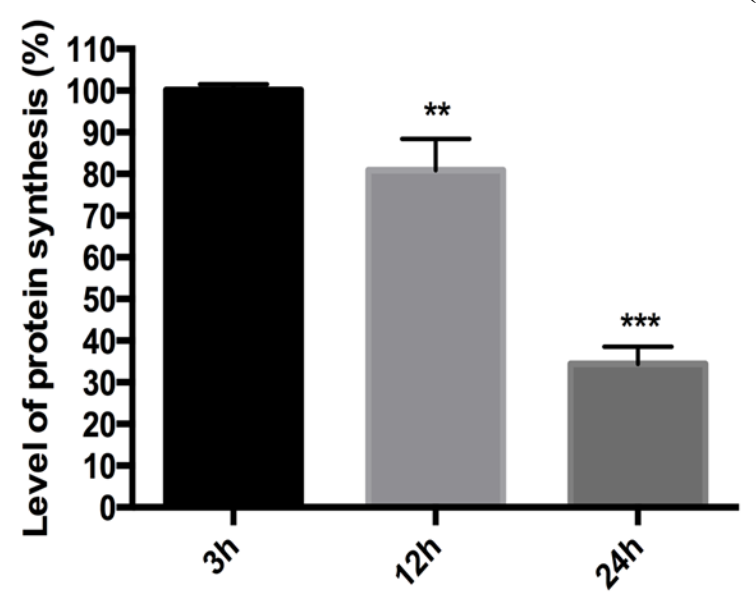

(b)

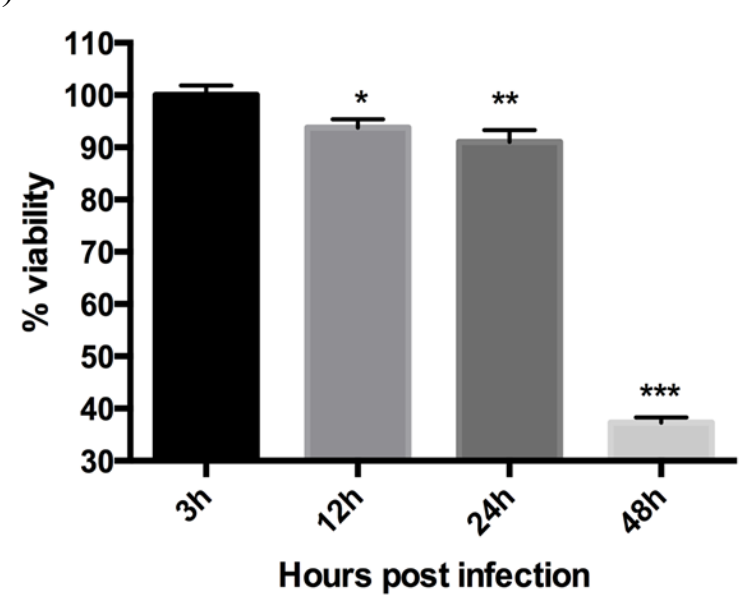

(c)

Figure 2. Infectious pancreatic necrosis virus induced inhibition of protein synthesis in CHSE 214 cells. Cells were first infected and, at indicated times, proteins synthesized were labeled using $\mathrm{S}^{35}$ Methionine and then harvested. (a) Prepared lysates were subjected to SDS-PAGE, blotted onto a PVDF membrane and autoradiographed in storage phosphor cassettes before analysis using the Typhoon. The numbers represent time in hours post infection; (b) Levels of protein synthesis expressed as percentages of the mock-infected cells after measurement of mean density protein amounts of three different bands using ImageQuant software (GE Healthcare). The results are representative of four independent experiments. ${ }^{*} p<0.05 ;{ }^{*} p<0.01$; (c) Cell viability post IPNV infection. Cells were infected with IPNV and cell viability was assayed at the indicated time post infection using CellTiter 96® AQueous One Solution assay (promega). The percent viability was calculated as described in the methodology section. Bars represent the average of 8 measurements taken from two independent infections \pm SD. ${ }^{*} p<0.05,{ }^{* *} p<0.01,{ }^{* * *} p<0.001$. 


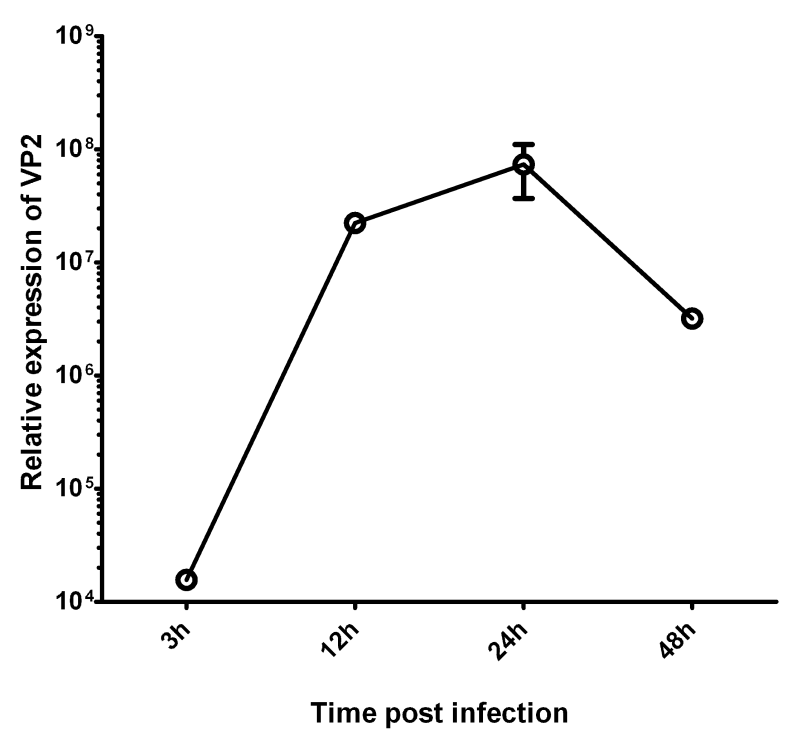

(a)

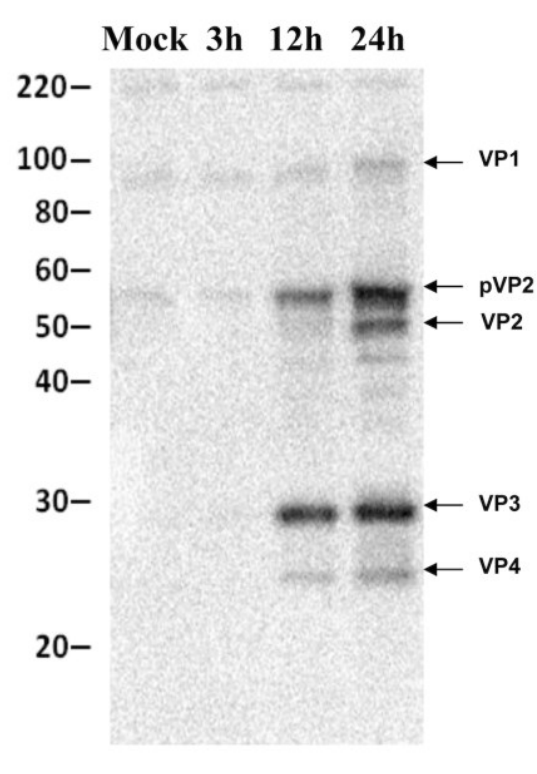

(b)

Figure 3. IPNV replication in virus-infected CHSE cells. (a) Relative expression of infectious pancreatic necrosis virus mRNA at different time post infection $(n=3)$; (b) Western blot analysis for IPNV proteins synthesis at different times post infection.

\subsection{IPNV Infection of CHSE Cells Results in eIF2 $\alpha$ Phosphorylation}

Phosphorylation of eIF2 $\alpha$ by different kinases is an important mechanism of protein synthesis regulation. In the present study, the onset of eIF $2 \alpha$ phosphorylation was 12 hpi (Figure 4) and coincided with that of protein synthesis inhibition (Figure 2). At $24 \mathrm{~h}$, the intensity of eIF2 $\alpha$ phosphorylation increased (Figure 4) while there were not enough proteins left from the infected cells at 48 hpi to allow assessment.

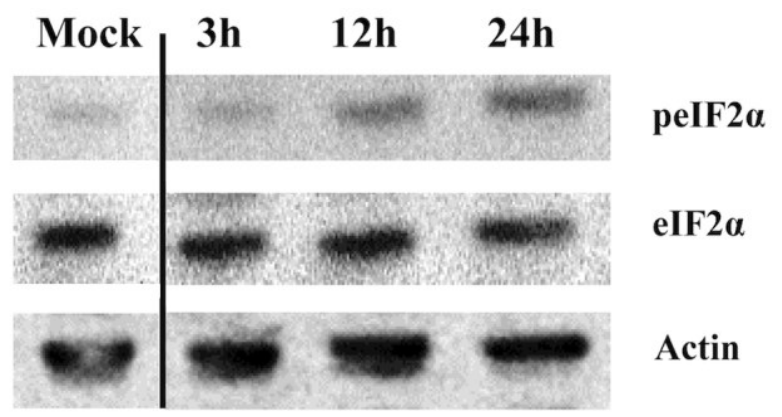

Figure 4. eIF2 $\alpha$ phosphorylation in IPNV-infected CHSE-214 cells. CHSE-214 cells were infected with IPNV, cells were lysed at the indicated time points, and lysates were subjected to Western blot analysis using rabbit polyclonal antibodies against the phosphorylated form of eIF $2 \alpha$ (Invitrogen). The blot is representative of a minimum of three independent observations. The numbers represent time in hours post infection. 


\subsection{The Effect of Protein Synthesis Inhibition on Type I IFN Response}

Inhibition of protein synthesis is a global effect at cellular level and thus affects IFN $\alpha$ expression per se and also downstream effector responses. Antibodies to salmon IFN $\alpha$ are not available to us and therefore we examined this effect by measuring IFN $\alpha$ mRNA levels. To estimate the production of IFN $\alpha$ at the protein level, an indirect approach using Mx1 and PKR mRNA expression, which comes down stream of IFN $\alpha$ signaling, was used. The results show that while IFN $\alpha$ mRNA gradually increased following infection (Figure 5a) and peaking at $24 \mathrm{hpi}, \mathrm{Mx} 1$ or PKR expression was not induced at any of the time points examined (3-48 hpi, Figure $5 \mathrm{~b}, \mathrm{c}$ ). Our interpretation is that IPNV signals off a response in the cell that interferes with IFN $\alpha$ responses, either through a direct impact on IFN $\alpha$ levels or indirectly through downstream effects of IFN $\alpha$.

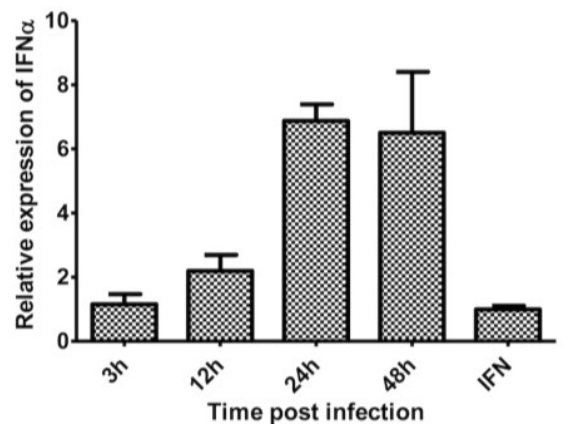

(a)

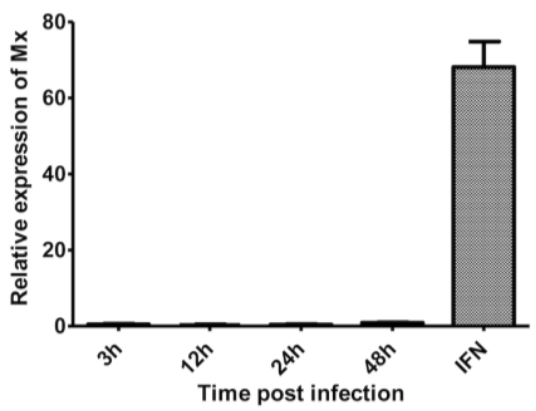

(b)

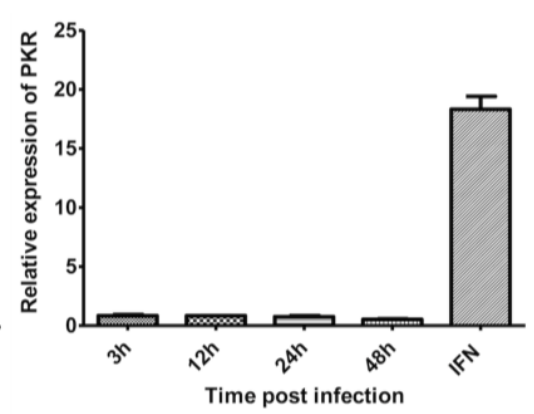

(c)

Figure 5. IFN $\alpha$ and Mx 1 mRNA expression in IPNV-infected CHSE-214 cells. CHSE-214 cells were infected with IPNV, harvested at indicated time points, and IFNa (a), Mx1 (b) and PKR (c) mRNA expression were measured by real-time PCR. IFN is cells treated with recombinant IFN $\alpha$ for 4 days and used as positive control $(n=3)$.

\subsection{IPNV Induces More Necrosis than Apoptosis at Early Time Post Infection}

Previous studies have shown that IPNV strains of serotype Ab induce apoptosis at early time post infection [29]. Since apoptotic cells exhibit decreased protein synthesis, this could serve as an explanation to the reduced protein synthesis referred above and therefore we needed to understand what role apoptosis played with regard to reduced protein synthesis. First, a DNA laddering assay was used. At 3 and 12 hpi, no DNA fragmentation was observed; however, at 24 and 48 hpi, fragmentation of DNA was visible (Figure 6), thus suggesting involvement of apoptosis. Since apoptosis-like DNA laddering is known to occur also as a result of necrosis [30,31], DNA laddering alone cannot fully distinguish between apoptosis and necrosis. The caspase 3 assay and flow cytometry were therefore used to validate these findings. In IPNV-infected cells, a significant increase in caspase 3 activity was observed both at $24(p<0.05)$ and 48 hpi $(p<0.001)$ (Figure 7), in agreement with the DNA laddering (Figure 6). Caspase 3 activity in staurosporine-treated cells (positive controls) was observed from $12 \mathrm{~h}$ post treatment and onwards (Figure 7). For flow cytometry, we used double-staining for annexin V (AV) and Propidium Iodide (PI) to represent apoptosis and necrosis, respectively. Cells that are $\mathrm{AV}^{+} / \mathrm{PI}^{-}$are apoptotic while $\mathrm{AV}^{+} / \mathrm{PI}^{+}$or $\mathrm{AV}^{-} / \mathrm{PI}^{+}$are necrotic [32]. IPNV-infected cells showed a marked increase for $\mathrm{AV}^{+} / \mathrm{PI}^{+}$staining from $12 \mathrm{~h}$ onwards (Figure 8; from 10 to $59 \%$ double-positive cells), demonstrating 
that the cells' membrane integrity was compromised. On the other hand, $\mathrm{AV}^{+} / \mathrm{PI}^{-}$stained cells remained low, and increased from 1 to $2 \%$ by $24 \mathrm{~h}$ and $1.7 \%$ by $48 \mathrm{~h}$.

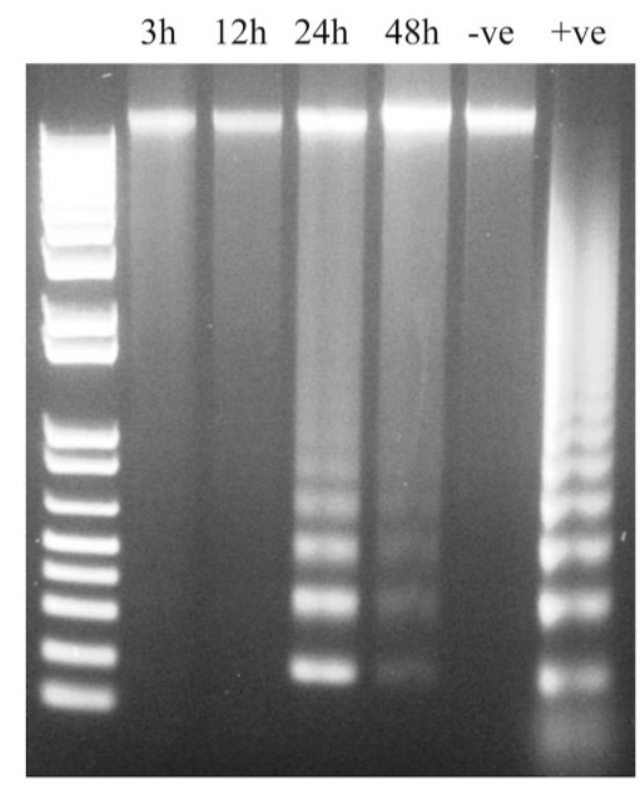

Figure 6. DNA laddering in IPNV-infected CHSE-214 cell lines. Cells were infected and harvested at the indicated time points. DNA was extracted using the Apoptotic DNA Ladder Kit (Roche) before being analyzed by gel electrophoresis. The result is representative of three independent experiments. -ve: uninfected cells; +ve: positive control.

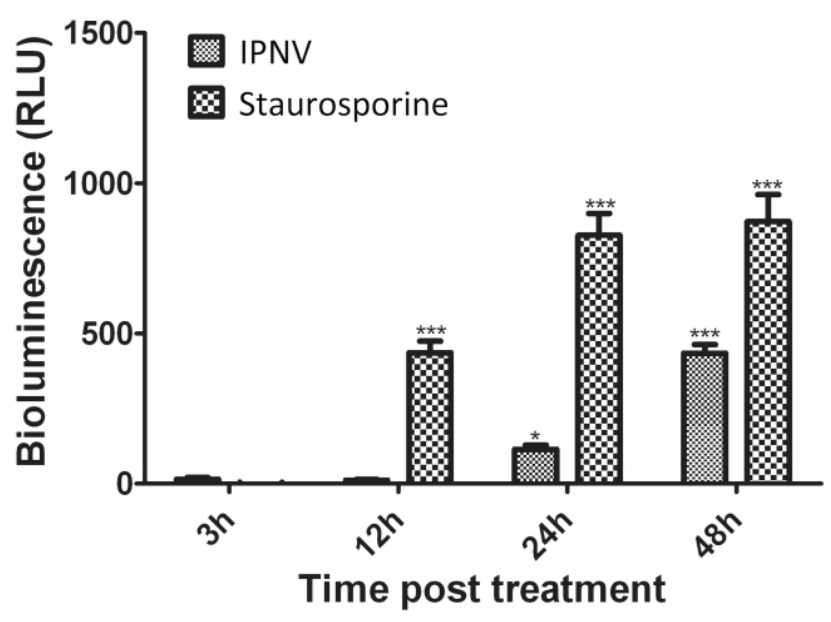

Figure 7. Caspase 3 activity in cells infected with infectious pancreatic necrosis virus. Cells were infected with IPNV or treated with $2.5 \mu \mathrm{M}$ staurosporine (positive control) for the indicated periods. Uninfected and untreated cells were used as negative controls. Caspase 3 activity was assessed by measuring the bioluminescence resulting from cleavage of a luminogenic substrate using Caspase-Glo ${ }^{\circledR} 3 / 7$ assay kit (promega). The bars represent the relative luminescence units after subtracting the mean values obtained from the uninfected/untreated cells. Bars represent means of data obtained from two independent experiments each conducted using three parallels \pm S.E.M. Statistical significance compared to cells treated at $3 \mathrm{~h}$ is indicated by asterisks; $*=p<0.05 ; * * *=p<0.001$. 


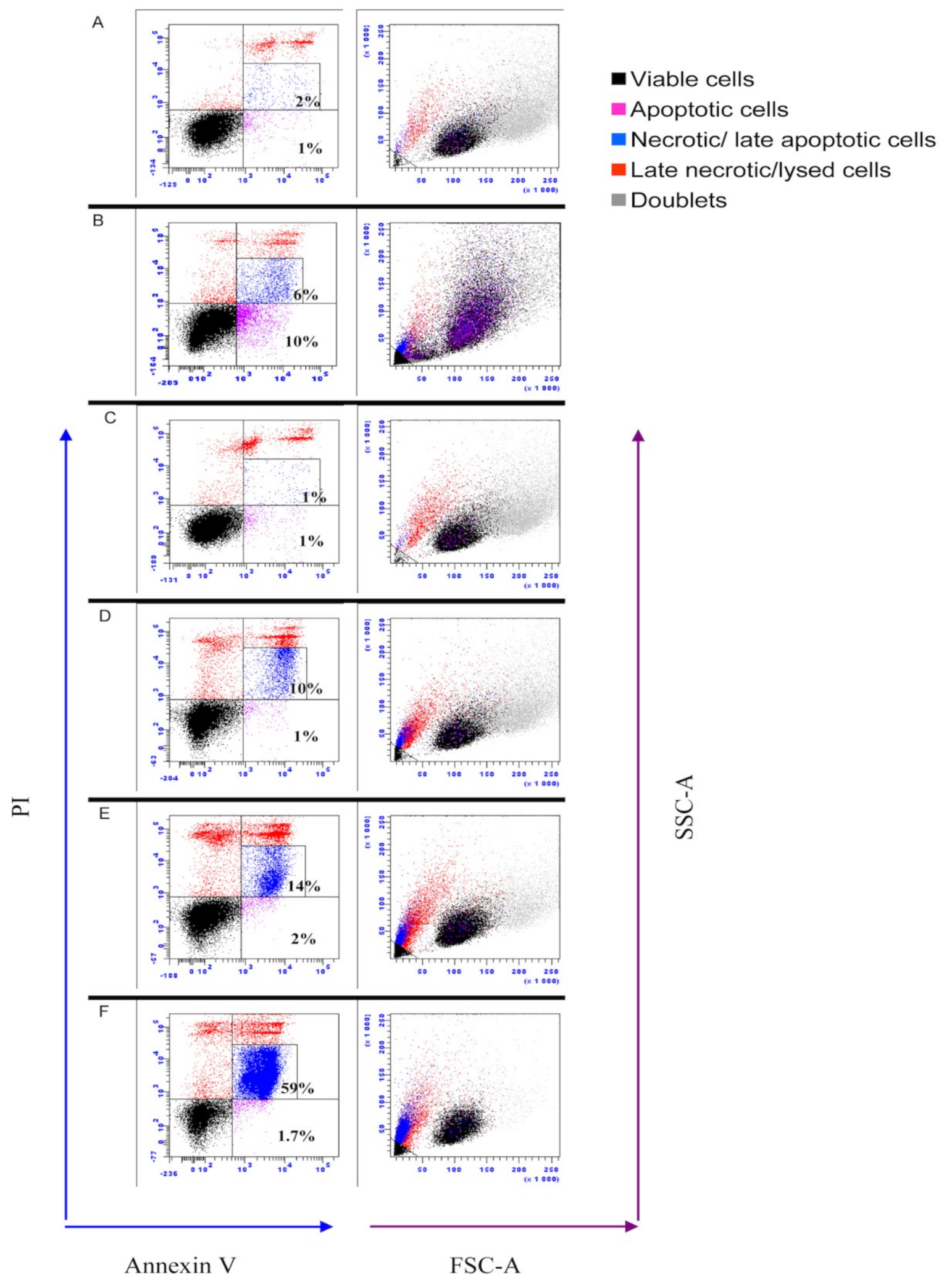

Figure 8. Flow cytometric analysis of infectious pancreatic necrosis virus-infected CHSE-214 cells. Cells were stained with annexin V and propidium iodide (PI) prior to analysis at prescribed time points. $\mathbf{A}=$ non infected cells; $\mathbf{B}=$ cells treated with staurosporine for $48 \mathrm{~h}$ to induce apoptosis; C-F = IPNV-infected cells for 3, 12, 24 and $48 \mathrm{~h}$, respectively. Necrotic cells (blue) have low forward (FSC-A) and side scatter (SSC-A) values. Results provided are representative of at least four independent observations. 


\section{Discussion}

Here we show for the first time that infectious pancreatic necrosis virus induces inhibition of protein synthesis in the permissive cell line, CHSE. The inhibition involves phosphorylation of eIF2 $\alpha$ (from 12 hpi and onwards). While apoptosis plays less of a role in protein synthesis inhibition, and DNA laddering is seen by $24 \mathrm{hpi}$, the highest percentage of apoptotic by 24 hpi is $2 \%$ by flow cytometry. Despite cellular protein shutdown, virus replication peaks at 24 hpi and a drop in cell viability is seen earliest at $48 \mathrm{hpi}$, coinciding with the loss of membrane integrity (by flow cytometry). Because inhibition of protein synthesis did not hinder virus production, we propose this is a strategy of the virus to circumvent IFN $\alpha$-induced cellular, antiviral mechanisms and to induce cell lysis in order to facilitate its release from infected cells.

Phosphorylation of eIF2 $\alpha$ and the subsequent inhibition of protein synthesis are important host defensive mechanisms to limit the replication of RNA viruses [33]. eIF2 $\alpha$ phosphorylation following IPNV infection (Figure 4) is consistent with a previous report [21] and results in inhibition of protein synthesis in CHSE-214 cells. Two kinases have been shown to play roles in eIF2 $\alpha$ phosphorylation during virus infections in higher vertebrates, namely the PKR and PERK [1,3]. Fish possess an additional kinase named Z-DNA binding protein kinase (PKZ) and Atlantic salmon PKZ has been shown to phosphorylate eIF $2 \alpha$ in response to Z-DNA, but its activation by Z-dsRNA has not yet been demonstrated [34]. Antibodies against PKR, PERK, or their phosphorylated forms are not available for salmonids at the moment. It was therefore difficult for us to further study and demonstrate the mechanisms by which eIF2 $\alpha$ is induced. Both PKR and PERK have been suggested to be involved in inducing cell death following IPNV infection [35]. Indeed, high virus replication and protein synthesis as observed in this study and accumulation of folded proteins may have led to PERK activation as a consequence of ER stress followed by eIF2 $\alpha$ phosphorylation. However, ER-stress response has only been shown to occur during infection with enveloped viruses [36]. PKR, on the other hand, is found in the cytoplasm where IPNV replication occurs. In fact, IPN viral RNA is exposed in the cytoplasm and can be detected in infected cells during replication through various receptors [37]. Despite PKR not being found as upregulated, basal levels of PKR could be responsible for eIF $2 \alpha$ phosphorylation during IPNV infection. However, additional studies should be performed to elucidate this in detail.

Contradicting reports have been published regarding the occurrence of apoptosis following IPNV infections [29,38-41]. Since eIF2 $\alpha$ has previously been implicated in decreased protein synthesis of apoptotic cells [42], we needed to understand to what extent apoptosis per se contributed to protein shutdown. All apoptosis assays used in the present study, namely DNA laddering, caspase 3 and flow cytometry, showed that apoptosis occurred from $24 \mathrm{~h}$ onwards (Figures 6, 7 and 8), but the fraction of apoptotic cells is very small, based on flow cytometry (Figure 8), which is consistent with our earlier results [41]. Intriguingly, loss of membrane integrity as detected by PI staining (Figure 8) appears earlier than apoptosis, similar to the findings of some [38] but at variance with results of others $[29,39,41]$. The differences in apoptosis/necrosis profiles between our findings and other researchers [29,38-41] demonstrate that different IPNV isolates are associated with variable apoptotic/necrotic characteristics. Care should therefore be taken not to generalize results beyond isolates or geno-groups.

Perforation of cell membranes and the subsequent changes in membrane permeability in virus-infected cells may occur at early stages due to virus entry, during virus maturation or late stages 
of virus replication resulting in cell lysis and virus release [43]. It has also been suggested that permeability changes may be essential for cells to switch from synthesis of cell proteins to virus proteins [43]. Forming of pores during the entry process is sensitive to the concentration of extracellular $\mathrm{Ca}^{2+}$ and can be inhibited by higher concentrations [43]. In the present study, changes in membrane permeability started at middle stages of virus replication (12 hpi) and reached the peak at late stages of virus replication with the onset of cell lysis. No change in membrane permeability was detected at early stages. This suggests that changes in membrane permeability during IPNV infection may be essential for virus replication and/or release. This is similar to what has been found for infectious bursal disease (IBDV), another member of the family Birnaviridae [44] where no virus was rescued after disrupting the pore forming mechanism by mutagenesis. Pore formation by IBDV could also be inhibited by increasing $\mathrm{Ca}^{2+}$ concentrations. The ability of IPNV to perforate cell membranes is yet to be demonstrated. However, high extracellular $\mathrm{Ca}^{2+}$ was shown to decrease plaque formation in CHSE cells while the opposite was observed when extracellular $\mathrm{Ca}^{2+}$ was decreased or with $\mathrm{Ca}^{2+}$ blockers [45].

To overcome the effect of protein shutdown, several species of RNA viruses have evolved a cap-independent (eIF2 $\alpha$-independent) mechanism of initiation of translation. For example, viruses belonging to the family Picornaviridae possess internal ribosome entry sites (IRES) that enable them to preferentially translate their proteins in a cap-independent manner [46]. Hantaviruses have a unique cap-independent mechanism by which they utilize their nucleocapsid protein to replace all or part of the cap-binding complex [47]. For the Birnaviridae family, there is limited information on the initiation of translation and replication and it is not known if they possess a ribosome entry site (IRES) of normal (i.e., >300 nt) length or another mechanism that is needed to recruit host cell-encoded initiation factors [48]. We found that eIF2 $\alpha$ phosphorylation was induced as early as 12 hpi and the phosphorylation levels continued to increase for the duration of the infection cycle accompanied by marked inhibition of cellular protein synthesis (Figures 2 and 7). On the other hand, virus protein synthesis increased during the time of host protein inhibition (Figure 3b). What mechanisms are used by IPNV to initiate translation under these circumstances remains unresolved and additional studies are needed to understand this in more detail.

Inhibition of protein synthesis is a double-edged sword; whereas it is an important defensive tool for the host cell [49], it nevertheless limits the antiviral effects downstream of interferon responses, and can thus be a survival strategy for the virus [50]. Previous studies show that IPNV infections do not suppress IFN production but interfere with downstream signaling [51]. Skjesol et al. [52] confirmed this and further demonstrated that IPNV infections are able to attenuate IFN induced responses even when the cells were pretreated with IFN for $4 \mathrm{~h}$. Herein we show that inhibition of protein synthesis was induced while virus replication was at its highest (Figures 2 and 3) and with a parallel increase of IFN $\alpha$ mRNA expression (Figure 8a). Regardless, neither Mx1 nor PKR mRNA was induced and from this we interpret the results to imply that IPNV induced inhibition of protein synthesis may serve as a strategy for the virus to evade or attenuate interferon-induced anti-viral responses and/or to facilitate the release of viral progeny.

Inhibition of protein synthesis post IPNV infection found here is in contrast with previous reports where no protein inhibition was observed following infection of RTG cells although host DNA synthesis was inhibited $[19,20,53]$. The reasons for this are not clear but there are several differences between the present study and the previous ones. We used CHSE cells instead of RTG-2 cells but we consider it 
unlikely that this would account for the particular differences observed since the isolate used has also the ability to inhibit protein synthesis in RTG-2 cells [22]. Moreover, the virus isolates used in previous studies are different from ours; they used the so-called Dry Mills strain [19,20], which is closely related to AF343571 and isolate VR-299 [53]. Both isolates belong to the North American West Buxton (WB) serotype (serotype A1); we used an Sp serotype (serotype A2) that is antigenically and pathogenically distant from the WB isolates [54] in the present study. In addition to this, there are differences in the multiplicity of infections used or the time of sampling. While Nicholson and Lothrop used very high MOI, 100TCID50/Cell [19,20], Dobos used similar MOI to ours, $20 \mathrm{PFU/cell,} \mathrm{but} \mathrm{the} \mathrm{last} \mathrm{sample} \mathrm{was} \mathrm{obtained}$ at 12 hpi which in our study was found to be the start of protein inhibition [53].

\section{Acknowledgement}

The authors wish to acknowledge the Oslo University Hospital Flow Cytometry Core Facility, especially Hans Christian Dalsbotten Aass for their assistance with flow cytometry. This research is partly supported by a project of Øystein Evensen from the Research Council of Norway, project number 183204, Indo-Norwegian platform on fish and shellfish vaccine development.

\section{Author Contributions}

AAG contributed to the planning of the research experiment, carried out the work in the lab, analyzed the data and contributed to the writing of the manuscript; SM contributed to the planning of the research experiment, participated in analyzing the data, and contributed to the writing of the manuscript; $\varnothing \mathrm{E}$ contributed to the planning of the research experiment, participated in interpreting the data, contributed to the writing of the manuscript, and provided the funding.

\section{Conflict of Interest}

The authors declare no conflict of interest.

\section{References}

1. Su, Q.Z.; Wang, S.; Baltzis, D.; Qu, L.K.; Raven, J.F.; Li, S.Y.; Wong, A.H.T.; Koromilas, A.E. Interferons induce tyrosine phosphorylation of the eIF2 alpha kinase PKR through activation of Jak1 and Tyk2. EMBO Rep. 2007, 8, 265-270.

2. Asano, K.; Clayton, J.; Shalev, A.; Hinnebusch, A.G. A multifactor complex of eukaryotic initiation factors, eIE1, eIF2, eIF3, eIF5, and initiator tRNA(Met) is an important translation initiation intermediate in vivo. Genes Dev. 2000, 14, 2534-2546.

3. Medigeshi, G.R.; Lancaster, A.M.; Hirsch, A.J.; Briese, T.; Lipkin, W.I.; Defilippis, V.; Fruh, K.; Mason, P.W.; Nikolich-Zugich, J.; Nelson, J.A. West Nile virus infection activates the unfolded protein response, leading to CHOP induction and apoptosis. $J$ Virol. 2007, 81, 10849-10860.

4. Barber, G.N. Host defense, viruses and apoptosis. Cell Death Differ. 2001, 8, 113-126.

5. Marissen, W.E.; Lloyd, R.E. Eukaryotic translation initiation factor $4 \mathrm{G}$ is targeted for proteolytic cleavage by caspase 3 during inhibition of translation in apoptotic cells. Mol. Cell. Biol. 1998, 18, $7565-7574$. 
6. Gradi, A.; Svitkin, Y.V.; Imataka, H.; Sonenberg, N. Proteolysis of human eukaryotic translation initiation factor eIF4GII, but not eIF4GI, coincides with the shutoff of host protein synthesis after poliovirus infection. Proc. Natl. Acad. Sci. USA 1998, 95, 11089-11094.

7. Joachims, M.; van Breugel, P.C.; Lloyd, R.E. Cleavage of poly(A)-binding protein by enterovirus proteases concurrent with inhibition of translation in vitro. J. Virol. 1999, 73, 718-727.

8. Vende, P.; Piron, M.; Castagne, N.; Poncet, D. Efficient translation of rotavirus mRNA requires simultaneous interaction of NSP3 with the eukaryotic translation initiation factor eIF4G and the mRNA 3' end. J. Virol. 2000, 74, 7064-7071.

9. Piron, M.; Vende, P.; Cohen, J.; Poncet, D. Rotavirus RNA-binding protein NSP3 interacts with eIF4GI and evicts the poly(A) binding protein from eIF4F. EMBO J. 1998, 17, 5811-5821.

10. Etchison, D.; Milburn, S.C.; Edery, I.; Sonenberg, N.; Hershey, J.W.B. Inhibition of Hela-Cell Protein-Synthesis Following Poliovirus Infection Correlates with the Proteolysis of A 220,000-Dalton Polypeptide Associated with Eukaryotic Initiation Factor-Iii and A Cap BindingProtein Complex. J. Biol. Chem. 1982, 257, 4806-4810.

11. Khoo, D.; Perez, C.; Mohr, I. Characterization of RNA determinants recognized by the arginineand proline-rich region of Us11, a herpes simplex virus type 1-encoded double-stranded RNA binding protein that prevents PKR activation. J. Virol. 2002, 76, 11971-11981.

12. Spurgeon, M.E.; Ornelles, D.A. The Adenovirus E1B 55-Kilodalton and E4 Open Reading Frame 6 Proteins Limit Phosphorylation of eIF2 alpha during the Late Phase of Infection. J. Virol. 2009, 83, 9970-9982.

13. Dobos, P. The molecular biology of infectious pancreatic necrosis virus (IPNV). Annu. Rev. Fish Dis. 1995, 5, 25-54.

14. Havarstein, L.S.; Kalland, K.H.; Christie, K.E.; Endresen, C. Sequence of the Large Double-Stranded-RNA Segment of the N1 Strain of Infectious Pancreatic Necrosis Virus-A Comparison with Other Birnaviridae. J. Gen. Virol. 1990, 71, 299-308.

15. Magyar, G.; Dobos, P. Evidence for the Detection of the Infectious Pancreatic Necrosis Virus Polyprotein and the 17-Kda Polypeptide in Infected-Cells and of the Ns Protease in Purified Virus. Virology 1994, 204, 580-589.

16. Duncan, R.; Nagy, E.; Krell, P.J.; Dobos, P. Synthesis of the Infectious Pancreatic Necrosis Virus Polyprotein, Detection of A Virus-Encoded Protease, and Fine-Structure Mapping of Genome Segment-A Coding Regions. J. Virol. 1987, 61, 3655-3664.

17. Macdonald, R.D.; Dobos, P. Identification of the Proteins Encoded by Each Genome Segment of Infectious Pancreatic Necrosis Virus. Virology 1981, 114, 414-422.

18. Duncan, R.; Mason, C.L.; Nagy, E.; Leong, J.A.; Dobos, P. Sequence-Analysis of Infectious Pancreatic Necrosis Virus Genome Segment-B and Its Encoded VP1 Protein-A Putative RNA-Dependent RNA-Polymerase Lacking the Gly Asp Asp Motif. Virology 1991, 181, 541-552.

19. Lothrop, D.; Nicholson, B.L. Inhibition of Cellular DNA-Synthesis in Cells Infected with Infectious Pancreatic Necrosis Virus. J. Virol. 1974, 14, 485-492.

20. Nicholson, B.L. Macromolecule Synthesis in RTG-2 Cells Following Infection with Infectiouus Pancreatic Necrosis (IPN) Virus. J. Gen. Virol. 1971, 13, 369-372. 
21. Garner, J.N.; Joshi, B.; Jagus, R. Characterization of rainbow trout and zebrafish eukaryotic initiation factor 2 alpha and its response to endoplasmic reticulum stress and IPNV infection. Dev. Comp. Immunol. 2003, 27, 217-231.

22. Chen, L.; Evensen, Ø.; Mutoloki, S. Delayed protein shut down and cytopathic changes lead to high yields of infectious pancreatic necrosis virus cultured in Asian Grouper cells. J. Virol. Methods 2014, 195, 228-235.

23. Lannan, C.N.; Winton, J.R.; Fryer, J.L. Fish cell lines: Establishment and characterization of nine cell lines from salmonids. In Vitro 1984, 20, 671-676.

24. Munang'andu, H.M.; Fredriksen, B.N.; Mutoloki, S.; Brudeseth, B.; Kuo, T.Y.; Marjara, I.S.; Dalmo, R.A.; Evensen, O. Comparison of vaccine efficacy for different antigen delivery systems for infectious pancreatic necrosis virus vaccines in Atlantic salmon (Salmo salar L.) in a cohabitation challenge model. Vaccine 2012, 30, 4007-4016.

25. Song, H.C.; Santi, N.; Evensen, O.; Vakharia, V.N. Molecular determinants of infectious pancreatic necrosis virus virulence and cell culture adaptation. J. Virol. 2005, 79, 10289-10299.

26. Evensen, O.; Rimstad, E. Immunohistochemical identification of infectious pancreatic necrosis virus in paraffin-embedded tissues of Atlantic salmon (Salmo salar). J. Vet. Diagn. Invest 1990, 2, 288-293.

27. Xu, C.; Guo, T.C.; Mutoloki, S.; Haugland, O.; Marjara, I.S.; Evensen, O. Alpha Interferon and Not Gamma Interferon Inhibits Salmonid Alphavirus Subtype 3 Replication In Vitro. J. Virol. 2010, 84 , 8903-8912.

28. Livak, K.J.; Schmittgen, T.D. Analysis of relative gene expression data using real-time quantitative PCR and the 2(-Delta Delta C(T)) Method. Methods 2001, 25, 402-408.

29. Hong, J.R.; Lin, T.L.; Hsu, Y.L.; Wu, J.L. Apoptosis precedes necrosis of fish cell line with infectious pancreatic necrosis virus infection. Virology 1998, 250, 76-84.

30. Dong, Z.; Saikumar, P.; Weinberg, J.M.; Venkatachalam, M.A. Internucleosomal DNA cleavage triggered by plasma membrane damage during necrotic cell death-Involvement of serine but not cysteine proteases. Am. J. Pathol. 1997, 151, 1205-1213.

31. Didenko, V.V.; Ngo, H.; Baskin, D.S. Early necrotic DNA degradation-Presence of blunt-ended DNA breaks, 3 ' and 5 ' overhangs in apoptosis, but only 5 ' overhangs in early necrosis. Am. J. Pathol. 2003, 162, 1571-1578.

32. Honda, O.; Kuroda, M.; Joja, I.; Asaumi, J.; Takeda, Y.; Akaki, S.; Togami, I.; Kanazawa, S.; Kawasaki, S.; Hiraki, Y. Assessment of secondary necrosis of Jurkat cells using a new microscopic system and double staining method with annexin $\mathrm{V}$ and propidium iodide. Int. J. Oncol. 2000, 16, 283-288.

33. Garcia, M.A.; Meurs, E.F.; Esteban, M. The dsRNA protein kinase PKR: Virus and cell control. Biochimie 2007, 89, 799-811.

34. Bergan, V.; Jagus, R.; Lauksund, S.; Kileng, O.; Robertsen, B. The Atlantic salmon Z-DNA binding protein kinase phosphorylates translation initiation factor 2 alpha and constitutes a unique orthologue to the mammalian dsRNA-activated protein kinase R. FEBS J. 2008, 275, 184-197.

35. Huang, H.L.; Wu, J.L.; Chen, M.H.; Hong, J.R. Aquatic birnavirus-induced ER stress-mediated death signaling contribute to downregulation of Bcl-2 family proteins in salmon embryo cells. PLOS ONE 2011, 6, e22935. 
36. He, B. Viruses, endoplasmic reticulum stress, and interferon responses. Cell Death Differ. 2006, 13, 393-403.

37. Espinoza, J.C.; Kuznar, J. Visualization of the infectious pancreatic necrosis virus replication cycle by labeling viral intermediates with a TUNEL assay. Vet. Microbiol. 2010, 143, 101-105.

38. Espinoza, J.C.; Cortes-Gutierrez, M.; Kuznar, J. Necrosis of infectious pancreatic necrosis virus (IPNV) infected cells rarely is preceded by apoptosis. Virus Res. 2005, 109, 133-138.

39. Hong, J.R.; Lin, T.L.; Hsu, Y.L.; Wu, J.L. Induction of apoptosis and secondary necrosis by infectious pancreatic necrosis virus in fish embryonic cells. J. Fish Dis. 1998, 21, 463-467.

40. Hong, J.R.; Gong, H.Y.; Wu, J.L. IPNVVP5, a novel anti-apoptosis gene of the Bcl-2 family, regulates Mcl-1 and viral protein expression. Virology 2002, 295, 217-229.

41. Santi, N.; Sandtro, A.; Sindre, H.; Song, H.C.; Hong, J.R.; Thu, B.; Wu, J.L.; Vakharia, V.N.; Evensen, O. Infectious pancreatic necrosis virus induces apoptosis in vitro and in vivo independent of VP5 expression. Virology 2005, 342, 13-25.

42. Jeffrey, I.W.; Bushell, M.; Tilleray, V.J.; Morley, S.; Clemens, M.J. Inhibition of protein synthesis in apoptosis: Differential requirements by the tumor necrosis factor alpha family and a DNA-damaging agent for caspases and the double-stranded RNA-dependent protein kinase. Cancer Res. 2002, 62, 2272-2280.

43. Pasternak, C.A. How Viruses Damage Cells-Alterations in Plasma-Membrane Function. J. Biosci. 1984, 6, 569-583.

44. Galloux, M.; Libersou, S.; Morellet, N.; Bouaziz, S.; Da Costa, B.; Ouldali, M.; Lepault, J.; Delmas, B. Infectious bursal disease virus, a non-enveloped virus, possesses a capsid-associated peptide that deforms and perforates biological membranes. J. Biol. Chem. 2007, 282, 20774-20784.

45. Kang, K.H.; Park, K.S.; Yoon, J.H.; Lee, C.H. Calcium response of CHSE following infection with infectious pancreatic necrosis virus (IPNV). Korean J. Microbiol. 1993, 31, 79-84.

46. Pelletier, J.; Kaplan, G.; Racaniello, V.R.; Sonenberg, N. Cap-independent translation of poliovirus mRNA is conferred by sequence elements within the 5' noncoding region. Mol. Cell Biol. 1988, 8 , 1103-1112.

47. Mir, M.A.; Panganiban, A.T. A protein that replaces the entire cellular eIF4F complex. EMBO J. 2008, 27, 3129-3139.

48. Boot, H.J.; Pritz-Verschuren, S.B. Modifications of the 3'-UTR stem-loop of infectious bursal disease virus are allowed without influencing replication or virulence. Nucleic Acids Res. 2004, 32 , 211-222.

49. Barry, G.; Breakwell, L.; Fragkoudis, R.; Attarzadeh-Yazdi, G.; Rodriguez-Andres, J.; Kohl, A.; Fazakerley, J.K. PKR acts early in infection to suppress Semliki Forest virus production and strongly enhances the type I interferon response. J. Gen. Virol. 2009, 90, 1382-1391.

50. Wertz, G.W.; Youngner, J.S. Interferon Production and Inhibition of Host Synthesis in Cells Infected with Vesicular Stomatitis Virus. J. Virol. 1970, 6, 476-484. 
51. Collet, B.; Munro, E.S.; Gahlawat, S.; Acosta, F.; Garcia, J.; Roemelt, C.; Zou, J.; Secombes, C.J.; Ellis, A.E. Infectious pancreatic necrosis virus suppresses type I interferon signalling in rainbow trout gonad cell line but not in Atlantic salmon macrophages. Fish Shellfish Immunol. 2007, 22, 44-56.

52. Skjesol, A.; Aamo, T.; Hegseth, M.N.; Robertsen, B.; Jorgensen, J.B. The interplay between infectious pancreatic necrosis virus (IPNV) and the IFN system: IFN signaling is inhibited by IPNV infection. Virus Res. 2009, 143, 53-60.

53. Dobos, P. Virus-Specific Protein-Synthesis in Cells Infected by Infectious Pancreatic Necrosis Virus. J. Virol. 1977, 21, 242-258.

54. Hill, B. J.; Way, K. Serological classification of infectious pancreatic necrosis (IPN) virus and other aquatic birnaviruses. Annu. Rev. Fish Dis. 1995, 5, 55-77.

(C) 2015 by the authors; licensee MDPI, Basel, Switzerland. This article is an open access article distributed under the terms and conditions of the Creative Commons Attribution license (http://creativecommons.org/licenses/by/4.0/). 